\title{
EXPLAINING ACTIVE AND PASSIVE TYPES OF COUNTERPRODUCTIVE WORK BEHAVIOR: THE MODERATION EFFECT OF BULLYING, THE DARK TRIAD AND JOB CONTROL
}

\section{ŁUKASZ BAKA}

Central Institute for Labour Protection - National Research Institute, Warsaw, Poland

Department of Ergonomy, Social Psychology Laboratory

\begin{abstract}
Objectives: Drawing on the stressor-emotion model, the study aimed to identify some predictors of the active and passive types of counterproductive work behavior (CWB). Specifically, 1) the direct effect of bullying on CWB, 2) the 2-way interaction effects of the Dark Triad (DT) and job control (JC), as well as 3$)$ the 3-way interaction effect $(\mathrm{DT} \times \mathrm{JC})$ on the bullying-CWB link were investigated. Material and Methods: Data were collected from 659 white- and blue-collar workers. The 2- and 3-way interactional effects were analyzed by means of PROCESS macros. Results: The analysis showed that high bullying was directly related to high active and passive types of CWB. The 2- and 3-way interactional effects were observed but only in relation to active (not passive) CWB. Bullying was associated with active CWB when the Dark Triad and job control were high. Conclusions: The study showed different ways of both types of CWB development. The findings provide further insight into processes leading to an increase in active and passive CWB. Int J Occup Med Environ Health. 2019;32(6):777-95
\end{abstract}

Key words:

job stress, job control, Dark Triad, organizational behavior, bullying at workplace, counterproductive work behavior

\section{INTRODUCTION}

Counterproductive work behavior (CWB), defined as involving intentional employee actions that harm, or are intended to harm, the organization and its members [1], has recently emerged as an important research topic in work and organizational psychology [2]. The stressoremotion (S-E) model describes how environmental and personal factors lead to CWB through the mediating processes of perception [1] and emotion [3]. This model indicates job stressors as the primary sources of CWB but the effect of job stressors can be modified by personality traits and job control (JC). Bullying at workplace, defined as the systematic persecution of a colleague, a subordinate or a superior [4], is a job stressor with a particularly negative impact on organizational behavior [5-8]. Various studies have revealed that a frequent behavioral response to bullying is engaging in actions detrimental to the organization. In recent years, the role of the Dark Triad (DT), including Machiavellianism, narcissism and psychopathy, has often been emphasized as a dispositional regulator of CWB [9-12]. The results of studies on the moderating role of JC in the context of CWB extension are confound-

\footnotetext{
Funding: this research was supported by the Central Institute for Labour Protection - National Research Institute in Warsaw (project No. I.N.01A entitled "Assessment of psychosocial risks in the groups of employees working in harmful conditions," within the scope of the fourth stage of the National Programme "Improvement of safety and working conditions" (2017-2019), project manager: Łukasz Baka).

Received: January 11, 2019. Accepted: July 15, 2019.

Corresponding author: Łukasz Baka, Central Institute for Labour Protection - National Research Institute, Department of Ergonomics, Social Psychology Laboratory, Czerniakowska 16, 00-701 Warsaw, Polska (e-mail: lubak@ciop.pl).
} 
ed [13-15]. Personality may be a factor modifying the relationship between JC and CWB.

The majority of the abovementioned studies have considered the general index of CWB, without differentiating between specific types of behavior, e.g., abuse, sabotage and withdrawal. It seems probable, however, that while experiencing mistreatment in the organization, employees with high levels of DT and JC tend to become involved into abuse and sabotage (treated as active types of CWB), i.e., are motivated by aggression and retaliation [16] which are impulsive and immediate, severely harmful, and oriented directly towards the source of stress (i.e., the bully as a person or the organization as a whole). Employees with high levels of DT and JC are less prone to demonstrate withdrawal (treated as a passive type of CWB), which is driven by the need to protect one's own resources [17] and involves distancing from job duties, working slowly and resorting to absenteeism. A high sense of JC can foster active forms of CWB, as it is linked to high autonomy in making decisions, the freedom of action and a higher probability of avoiding sanctions for non-ethical behavior [18].

The aim of the study is to identify job-related and personality-related predictors of the active and passive forms of CWB. In particular, this study investigated:

1) the main effect of bullying experience on the active and passive CWB;

2) the 2-way interaction effect of the Dark Triad on the bullying-CWB link (bullying $\times$ DT);

3) the 3-way interaction effect of the Dark Triad and JC on the bullying-CWB link (bullying $\times$ DT $\times$ job control).

\section{Counterproductive work behavior}

In addition to the popular distinction into interpersonal and organizational CWB [19], the division into active and passive forms of CWB was introduced by the authors of the S-E model [20]. Active behavior is immediately directed at a target (e.g., abuse and sabotage), and it is usually motivated by hostility and the need to retaliate for mis- treatment by the organization. Such overt harmful behaviors are visible and likely to be punished; therefore, passive and indirect behavior is more common, e.g., employee withdrawal, including taking longer breaks, being deliberately late for work, or intentionally working slowly.

The passive CWB may be motivated not only by the need to retaliate but also by the need to protect and retain one's resources under stressful conditions [20,21]. It may reflect attempts by employees to limit their exposure to stressful situations and prevent subsequent strain. This is consistent with the Conservation of Resources theory [17] which assumes that, in conditions of prolonged stress, people tend to save their resources, e.g., energy, time or social capital. Thus, decreasing the job involvement, shortening working time or being late can be some ways to conserve employees' own resources. It can be expected that the 2 groups of CWB may have different antecedents. The differences in the extension of the active types of CWB (e.g., abuse and sabotage) and withdrawal have been underlined in a recent meta-analysis [22].

In their typology of CWB, the authors of the S-E model differentiate among 5 patterns of harmful behavior in an organization, i.e., abuse, sabotage, theft, production deviance and withdrawal $[1,20]$. The first 2 patterns are treated by them as typical examples of an active form of CWB, motivated by the need to retaliate. Withdrawal is then presented as the most representative form of the passive CWB, guided by the need to protect one's resources [20]. The current study takes these 3 types of deviant behavior into consideration:

1) Abusing others denotes behavior intended to exert physical or mental harm on people related to the organization. It includes different forms of violent behavior, such as physical aggression, bullying, threats, offensive comments and obscene gestures [20].

2) Sabotage is purposefully harming, disturbing or boycotting organization's activities in order to achieve one's personal objectives [23]. Sabotage covers both mild forms of 
behavior, such as ignoring supervisor's comments, intended delays in doing one's work, making one's workplace dirty and propagating a negative image of the company, as well as more drastic forms which include damaging property owned by the employer, damaging equipment, breaking rules and regulations, failing to observe plans, abusing equipment or objects, and using more materials than necessary [24].

3) Organizational withdrawal is passive in nature and involves taking conscious actions aimed at reducing the amount of time spent on fulfilling one's professional duties, as well as limiting the amount of energy devoted to doing one's work [20]. Such behavior includes being intentionally late for work, reducing working time, extending breaks, abandoning one's work station, intentionally reducing productivity, taking days off in an unauthorized manner and faking illness.

Regardless of motivation, CWB is considered one of the most serious sources of costs incurred by organizations [25]. Such costs include financial losses, damage to the image of the organization and psychological consequences of these acts for employees. For example, it has been assessed that a significant number of employees engage in various types of CWB [26] and the annual estimated cost of such behavior is > USD 1 trillion: USD 120 billion from theft, USD 4.2 billion from workplace violence, and > USD 900 billion in lost income due to fraudulent activities [27]. Over $20 \%$ of HR managers reported incidents of physical violence in the workplace during the past 3 years [28]. It should come as no surprise that organizational researchers have investigated the potential antecedents of CWB and a mechanism for its development. Several studies have found linkages between CWB and both organizational and dispositional factors [29,30].

\section{The main effect of bullying at work on CWB}

Among organizational factors, job stressors are set apart as the key instigators. Their role in CWB formation is particularly emphasized in the S-E model [1]. The authors of the model treat CWB as a behavioral response to job stressors, but a negative impact of job stressors can be moderated by the employees' personality traits and the sense of control they experience in the workplace. It was found that different kinds of job stressors are related to CWB, e.g., interpersonal conflicts at work, organizational constraints, workload and role conflicts [1], injustice [16], job insecurity [31] and work-family or family-work conflicts [32].

In the current study, bullying at work was treated as a source of occupational stress. Bullying includes harassment, e.g., offending and socially excluding an employee, or making it difficult for them to perform tasks prescribed by their scope of work [33]. Bullying is not a single or isolated act, but a complex set of acts that is regularly targeted against an employee or a group of employees over a prolonged period of time. Previous studies have confirmed that abusive supervision [68], workplace incivility [5,34], negative climate at work [35], and aggression from supervisors and coworkers [36] are associated with active and passive types of CWB.

H1: Bullying is positively related to abuse, sabotage and withdrawal (main effect).

\section{The Dark Triad and its moderation effect}

Apart from the S-E model, a variety of leading job stress models are based on the assumption of an interaction between work and personal characteristics (e.g., Siegrist's effort-reward imbalance model). Some of these models have been recently extended by personal characteristics, such as the job demands-control-support (JDCS) model [37], the demandinduced strain compensation (DISC) model [38] and the job demands-resources (JD-R) model [39]. The moderating role of personality in the context of CWB is documented very well [40]. Some studies have found that agreeableness and conscientiousness [25], negative affectivity [34], hostile attribution [41], self-control [42] and locus of control [43] moderate the negative effect of different kinds of job stressors on dysfunctional behavior in an organization.

Recently, the role of "the dark side of personality" has been tested in the context of CWB [12]. The research 
has mainly focused on 3 traits, commonly referred to as the Dark Triad traits - Machiavellianism, narcissism and psychopathy [44]. Machiavellianism is characterized by cynical, pragmatic, misanthropic and immoral beliefs, emotional detachment, agentic and self-serving motives, strategic long-term planning, manipulation and exploitation $[45,46]$. Narcissism includes an inflated view of self, fantasies about control, success and admiration, and the desire to have self-love reinforced by others [47,48]. Psychopathy is marked by a lack of concern for both other people and social regulatory mechanisms, impulsivity, and a lack of guilt or remorse for harming others [49].

Some researchers claim that DT is a constellation of 3 theoretically separable components, which are actually linked [18]. In the opinion of the authors, combining them into a single personality dimension is not fully authorized. Other researchers suggest that a complex method should be used to investigate the "dark side" of personality, instead of single personality measures approached as isolated from one another $[50,12]$. These researchers treat DT as a group of 3 theoretically consistent characteristics forming a certain personality profile, showing the degree to which a human is Machiavellian, narcissistic and psychopathic. The Dark Triad components share an anti-social nature, crudeness, a lack of empathy and being mischievous in contacts with others [44]. The probability of the characteristics being revealed increases under stress (e.g., experiencing mobbing), when the available pool of cognitive resources is limited and, hence, the control of impulses and the adaptation of behavior to standards and social expectations require greater effort [51]. In addition to the similarities among the DT characteristics, they also demonstrate a positive relationship, which was regularly confirmed in studies. Correlations between the DT characteristics vary among groups and questionnaires, and reach the following values: $r \leq 0.61$ for Machiavellism and narcissism, $r \leq 0.67$ for Machiavellism and psychopathy, and $\mathrm{r} \leq 0.61$ for narcissism and psychopathy [52].
The DT concept is complementary to the Big Five, which is a popular and very useful concept, albeit with a few limitations. For example, it is a set of theoretically derived, descriptive adjectives, and it tends to tap better the "positive" aspects of people's personality over their "negative" sides $[53,54]$. Therefore, some authors underline the importance of researching also the "dark" sides of human nature [55,54]. This is even more so in light of the fact that the Big Five, according to Wu and Lebreton [56], describes only $5-10 \%$ of the variances of CWB.

A positive link between DT and CWB has been supported in several studies [12,18,53-55]. For instance, in a metaanalysis study, CWB was correlated strongly with Machiavellianism $(r=0.25)$ and narcissism $(r=0.43)$, and weakly with psychopathy $(r=0.06)$. In total, DT explained a $28 \%$ variance of CWB [12]. A few studies have also supported the moderating role of separated traits belonging to DT in the job stressors-CWB link. For instance, narcissism intensified the negative effect of organizational constraints [57], a lack of reciprocity [10] and interpersonal conflicts at work [11] on CWB. Boddy [9] has found, in turn, that employees with a high level of psychopathy, under conditions of high interpersonal conflicts and bullying, are the most frequently engaged in CWB. To the best of the author's knowledge, no study has tested the moderating effects of the global index of DT in the relationship between job stressors and CWB. Furthermore, in the studies cited above, the division into active and passive forms of CWB was not included.

$\mathrm{H} 2$ : The relationship between bullying and CWB is moderated by DT. Specifically, the negative effect of bullying on CWB is stronger in high DT employees than in low DT employees (the 2-way interaction).

\section{The moderated moderation effect of the Dark Triad and job control}

Apart from the modifying function of DT, the role of JC is emphasized as an important moderator of job stressors $[13,39]$. Job control is defined as the degree to which 
employees have the possibility of freely planning and completing work assignments, as well as influencing work conditions [58]. It may be viewed in 2 ways, i.e., as the autonomy of employees to act, and as their inclusion in the decision-making process.

According to the S-E model, JC reduces the negative effect of job stressors on CWB. Fox and Spector [59] point out 2 moments when JC is of great importance in the job stressor-behavior relation chain. The first is the moment of event perception and interpretation. The volume of control greatly determines if the event will be interpreted as a challenge or a hazard. The event interpretation method entails specific emotions. The other moment applies to the reaction upon experiencing negative emotions, and the ways to reduce them. Employees with high JC often tend to search for positive ways to relieve negative emotions, while employees with low JC would rather modify their work environment and restore their sense of control by means of acts of destruction [60].

Previous studies have not confirmed the buffering function of job control in the context of CWB [13-15]. For example, one of them found that JC moderates the negative effects of interpersonal conflicts at work and injustice on CWB, but both moderation effects were in a direction opposite to expectations [13]. High JC participants were more likely to report CWB when they reported high levels of stressors. Similar findings were obtained in a cross-lagged study on soldiers performing a peace mission. The soldiers who perceived JC as high, after 6 months of increasing work overload exhibited high levels of indiscipline [15].

To the best of the author's knowledge, the moderated moderation effect of DT and job control on the bullyingCWB link (the 3-way interaction) has not been examined but the expectation of this effect can be justified. According to the person-organization fit theory, people look for a work environment that will meet their needs, desires and preferences, as well as one that will remain in line with their values system [61]. It can be assumed that certain types of work environment and organizational culture are particularly attractive for "dark personalities" and that these attract them more strongly than other types of personality. As noted by Cohen [18], employees with DT feel more comfortable in a work setting that has much to offer in terms of their need for prestige, resources and independence. They also seek organizations where the probability of them being caught is lower because of the absence of clear policies and standards, as well as control mechanisms. These organizations are usually characterized by a high level of autonomy and decision latitude for employees, as well as a loose internal system of control [18]. Therefore, it may favor the emergence of harmful organizational behaviors, especially among workers with a high level of DT.

To a certain extent, this has been confirmed empirically [12,18,62]. For example, Cohen [18] has found that the link between DT and CWB is mediated by perceptions of organizational politics and moderated, among other things, by organizational transparency. It may be expected that employees high on DT feel more comfortable in a workplace where they have the ability to influence their work environment, and where they have freedom in decision-making and autonomy in actions. In other words, the manifestation of "dark traits" should be stronger in organizations where employees have a higher level of JC. Therefore, employees with high DT, who experience mistreatment in their organization and have a high level of $\mathrm{JC}$, are expected to be engaged in CWB more than workers with low JC.

The literature on aggression distinguishes between 2 forms of aggression based on underlying motives, i.e., hostile vs. instrumental [63]. Hostile aggression is associated with negative emotions, most typically anger, and it is often impulsive and has harm as its primary motive. Examples of organizational behavior motivated by hostile aggression are abuse (a direct form) and sabotage (an indirect form). Withdrawal is an example of instrumental aggression, and 
it is not necessarily associated with emotion, while it has some additional goals beyond harm [20]. It can be perceived as a way of coping [21,64,65].

According to the model of work frustration-aggression [66], when workers are mistreated by others, they experience frustration and tend to exact revenge. It can be expected that, for employees with a high level of DT, the most typical response to organizational mistreatment is an active form of CWB, which is usually immediate and facing the source of frustration directly. Several studies have found that DT is correlated with a tendency for aggressive responses [67], engagement in greater risk-taking activities [55], moral disengagement [68], high impetuosity, low self-control and low anxiety [69].

Furthermore, a high level of JC is connected with high autonomy, decision latitude, influence in the organization, as well as the sense of empowerment and impunity [59]. Therefore, it seems likely that, in response to bullying, employees with high levels of DT and JC are more engaged in active forms of CWB (abuse and sabotage) than in the passive one (withdrawal).

H3: The relationship between bullying and CWB is moderated by the joint effect of DT and JC. Specifically, the negative effect of bullying on CWB is the strongest for employees with a high level of DT and a high level of job control (the 3-way interaction).

H4: The 3-way interaction effect (bullying $\times$ DT $\times$ job control) is stronger for abuse and sabotage than for withdrawal.

\section{The control effect of social approval}

With regard to the fact that data concerning both the Dark Triad and non-ethical behavior constitute information that people do not confess to, one should expect a strong fear of assessment and the related self-presentation motivation. This is why the social approval effect was controlled in the presented study. The social approval applies to the self-presentation tendencies of the studied population to present themselves favorably. There can be several causes accounting for the trend, such as a lack of self-reflection, conformism, or pure inclination to lying and "pretending to be better" [70]. The self-presentation issues usually apply to 2 kinds of deformations. Firstly, members of the studied population may intentionally deny their weaknesses and vices, even if they are common in the society. Secondly, they can attribute to themselves some advantages or virtues which are very rare in the society, making it highly unlikely for them to possess them [70]. The role of using social approval inventories, thus, controls the degree to which the studied person gives a positive answer aimed at making a positive impression, while avoiding answers which describe the person just as he or she is.

\section{MATERIAL AND METHODS \\ Participants}

The study was conducted among Polish white- and bluecollar workers $(\mathrm{N}=659)$, such as civil servants, public administration officials, customer service employees, office personnel, production staff, and accountants. The questionnaires were distributed at randomly selected state-owned $(\mathrm{N}=364,55 \%)$ and private $(\mathrm{N}=295,45 \%)$ companies. A significant proportion of the participants $(\mathrm{N}=267,40 \%)$ were employed in managerial positions, while the rest $(\mathrm{N}=392,60 \%)$ were employed as executive workers.

Potential respondents received a hard copy of the questionnaires, along with a letter which explained the purpose of the study. Full confidentiality of data and anonymity were secured. Those who provided informed consent were asked to fill out the questionnaires and seal them in envelopes, which were subsequently collected by the research assistants. All participants were treated in accordance with the ethical guidelines of the Declaration of Helsinki. Out of 900 distributed questionnaires, 705 (78\%) were returned, and 659 (73\% of the original pool) were filled out at least in $75 \%$. These were subsequently used 
for the data analysis. The analyzed group consisted of 397 (60\%) women and $262(40 \%)$ men, aged 20-69 years (M $=37.24, \mathrm{SD}=8.79)$, with work experience of $1-40$ years $(\mathrm{M}=14.43, \mathrm{SD}=7.62)$.

\section{Measures}

Five tools were used in the study. Four of them (measuring bullying at work, JC, DT and CWB) were back translated into Polish. A questionnaire for social approval measurement was developed in Poland and is currently a fully validated method, which is commonly used for measurement of the variables in Polish studies.

\section{Bullying at work}

This variable was measured with the Negative Acts Questionnaires [71] in the Polish version [72]. The tool reflects typical bullying behaviors (e.g., giving unachievable tasks, making unkind gestures, spreading rumors). The participants indicated the degree to which they had suffered such behaviors during the last 6 months on a 5-point Likerttype rating scale, ranging from 1 (never) to 5 (daily). The scale has shown high reliability in the study $(\alpha=0.86)$.

\section{Job control}

Job control was measured with the subscale of the $J o b$ Content Questionnaire [57] in the Polish version [73]. This includes 9 items, of which 6 are related to skill discretion and 3 are related to decision authority. Each item of the subscale is evaluated on a 5-point response scale, ranging from 1 (totally disagree) to 5 (totally agree). The aggregated index of JC was taken into account in this study. Good internal reliability of the tools was shown with a Cronbach's $\alpha$ coefficient of 0.79 for JC.

\section{The Dark Triad}

To measure DT, the Dirty Dozen Scale was used [67] in the Polish version [74]. It is composed of 12 items (4 items per subscale). The participants were asked to what extent they agreed $(1=$ strongly disagree; $5=$ strongly agree $)$ with the statements. Corresponding items were averaged to create indexes for narcissism $(\alpha=0.83)$, Machiavellianism $(\alpha=0.78)$ and psychopathy $(\alpha=0.80)$, along with a composite of all 12 items $(\alpha=0.82)$.

\section{Counterproductive work behavior}

Counterproductive work behavior was measured with the 3 subscales of the short version of the Counterproductive Work Behavior-Checklist [20] (CWB-C32) in the Polish version [75]. These include abuse (e.g., harmful behaviors that affect other people), sabotage (e.g., destroying the physical environment) and withdrawal (e.g., avoiding work by being absent or late). The subscales consist of 17 items for abuse $(\alpha=0.88), 3$ items for sabotage $(\alpha=0.75)$ and 4 items for withdrawal $(\alpha=0.78)$, respectively. Responses are provided on a 5 -point scale, ranging from 1 (never) to 5 (every day).

\section{Social approval}

Social approval was measured with the Polish version of the Social Approval Questionnaire [76]. The questionnaire is based on a classical lie scale, taking into account socially non-approved but very common patterns of behavior, not considered pathological (e.g., "There were instances when I cheated somebody"), as well as socially desired but very unlikely behavior (e.g., "When I make a mistake, I am always ready to admit it"). The questionnaire consists of 29 statements with 2 possible answers $(1=$ true; 2 = false $)$. High results indicate a strong social approval.

\section{Analytical procedure}

All variables were Z-standardized. The missing data pattern was analyzed using Little's MCAR test, which confirmed that data were missing completely at random, $\chi^{2}(71)=49.78, p=0.684$. The research model was tested by means of a regression analysis with bootstrapping, 
using PROCESS macros [77]. Model 3 was applied (the moderated moderation effect). By applying bootstrapping (1000 samples), PROCESS calculates direct, moderation and moderated moderation effects - for low ( $-1 \mathrm{SD})$, mean $(\mathrm{M})$ and high (+1 SD) levels of the moderators - as well as their confidence intervals (CIs).

For each of the 3 types of CWB (dependent variables), the analyses were run separately. This means that a type of CWB was regressed on bullying, DT and JC (main effects), and then on interactional effects: 1 ) bullying $\times$ DT, 2) bullying $\times$ JC, 3) DT $\times$ JC, 4) bullying $\times$ DT $\times$ JC. The test of slope differences was performed if the interaction was significant [78]. The effects of gender, age, job seniority and the need for approval were controlled in each regression model.

\section{RESULTS}

\section{Descriptive statistics}

Means, standard deviations and Pearson's correlations are displayed in Table 1. Age and job seniority were shown to correlate negatively with bullying, DT and CWB. Gender was found to be positively related to DT and CWB (sabotage only), and negatively to JC, with men displaying higher DT $(\mathrm{t}=-6.77, \mathrm{p}<0.001)$, more frequent CWB $(\mathrm{t}=-2.44, \mathrm{p}<0.05)$ and lower JC $(\mathrm{t}=2.98, \mathrm{p}<0.01)$ than women. Social approval correlated negatively with DT and the 3 types of CWB - abuse, sabotage and withdrawal. When it comes to differences in the levels of DT and CWB, in relation to the employment sector (public vs. private), job position (managerial vs. non-managerial) and the type of work (manual vs. intellectual), the analysis found that employees in the private sector showed higher levels of DT $(\mathrm{t}=-4.45, \mathrm{p}<0.001)$ and a higher frequency of CWB $(t=-3.81, p<0.001)$. The remaining variables do not seem to be connected significantly with either DT or CWB.

The 3 "dark traits" correlated positively with each other, the same as the 3 types of CWB. Each "dark trait" cor- related positively with bullying and the 3 forms of CWB. Bullying at work was negatively related to JC and positively to CWB. The Fisher test found that bullying is correlated weaker with withdrawal, in comparison with abuse and sabotage $(z=1.65 ; p<0.05)$.

\section{Testing hypothesis}

Table 2 displays the results of regression analyses testing the main effect of bullying at work, DT and JC on CWB, as well as the 2- and 3-way interactional effects. In these analyses, the effects of gender, age, job seniority and the need for approval were controlled. Age and job seniority were not a predictor of $\mathrm{CWB}$, while gender predicted only sabotage, but very weakly. The need for approval was a predictor of the 3 types of CWB. A high level of the need for approval predicted a low level of CWB.

The findings confirmed the statistical significance of 2 (of 3) main effects. High levels of bullying and DT (but not JC) are predictors of the 3 types of CWB (Table 2). In particular, high bullying at work predicted high levels of abuse ( $\mathrm{B}=0.43,95 \% \mathrm{CI}: 0.32-0.55)$, sabotage $(\mathrm{B}=0.37,95 \% \mathrm{CI}: 0.25-0.51)$ and withdrawal $(\mathrm{B}=0.26$, 95\% CI: 0.15-0.36). Similarly, DT was positively related to the 3 types of CWB (for abuse: $\mathrm{B}=0.27,95 \% \mathrm{CI}$ : $0.21-0.34$; for sabotage: $\mathrm{B}=0.19,95 \% \mathrm{CI}: 0.11-0.27$; for withdrawal: $\mathrm{B}=0.36,95 \% \mathrm{CI}: 0.28-0.43$, respectively).

Table 2 shows that DT moderates the negative effect of bullying at work on abuse (B $=0.30,95 \% \mathrm{CI}$ : $0.20-0.41)$, sabotage $(\mathrm{B}=0.28,95 \% \mathrm{CI}: 0.17-0.39)$ and withdrawal ( $\mathrm{B}=0.14,95 \%$ CI: $0.07-0.22$ ). Figures $1-3$ show that the higher the level of bullying, the higher the levels of abuse, sabotage and withdrawal, but only when DT is also high. The results of the stepwise regression analysis showed that the 2-way interaction effects were stronger for abuse and sabotage (active CWB) than for withdrawal (passive CWB). The 2-way interaction effects explain $12 \%$ of abuse, $11 \%$ of sabotage and only $3 \%$ of withdrawal variances. The results partially confirm $\mathrm{H} 2$. 


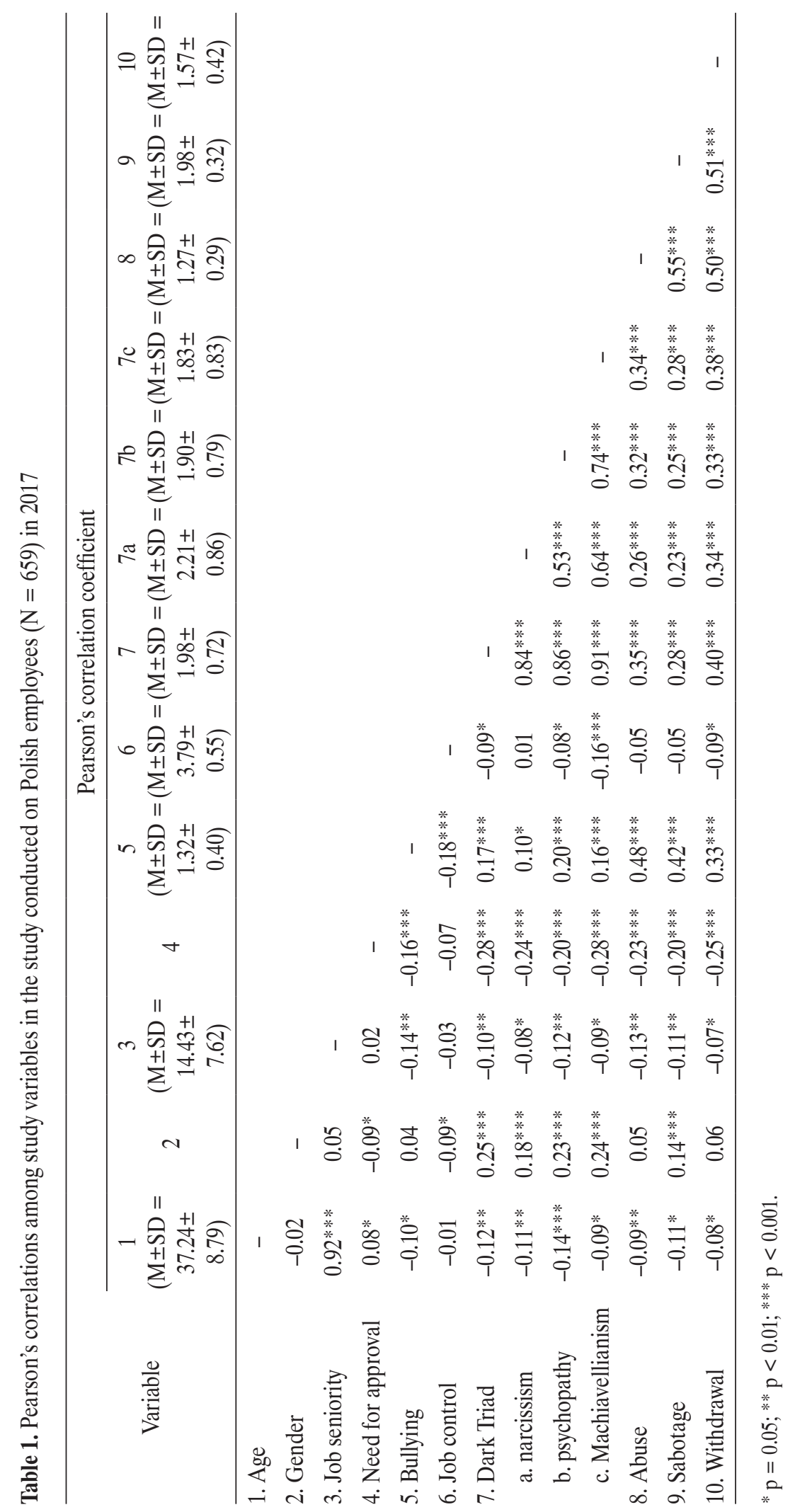




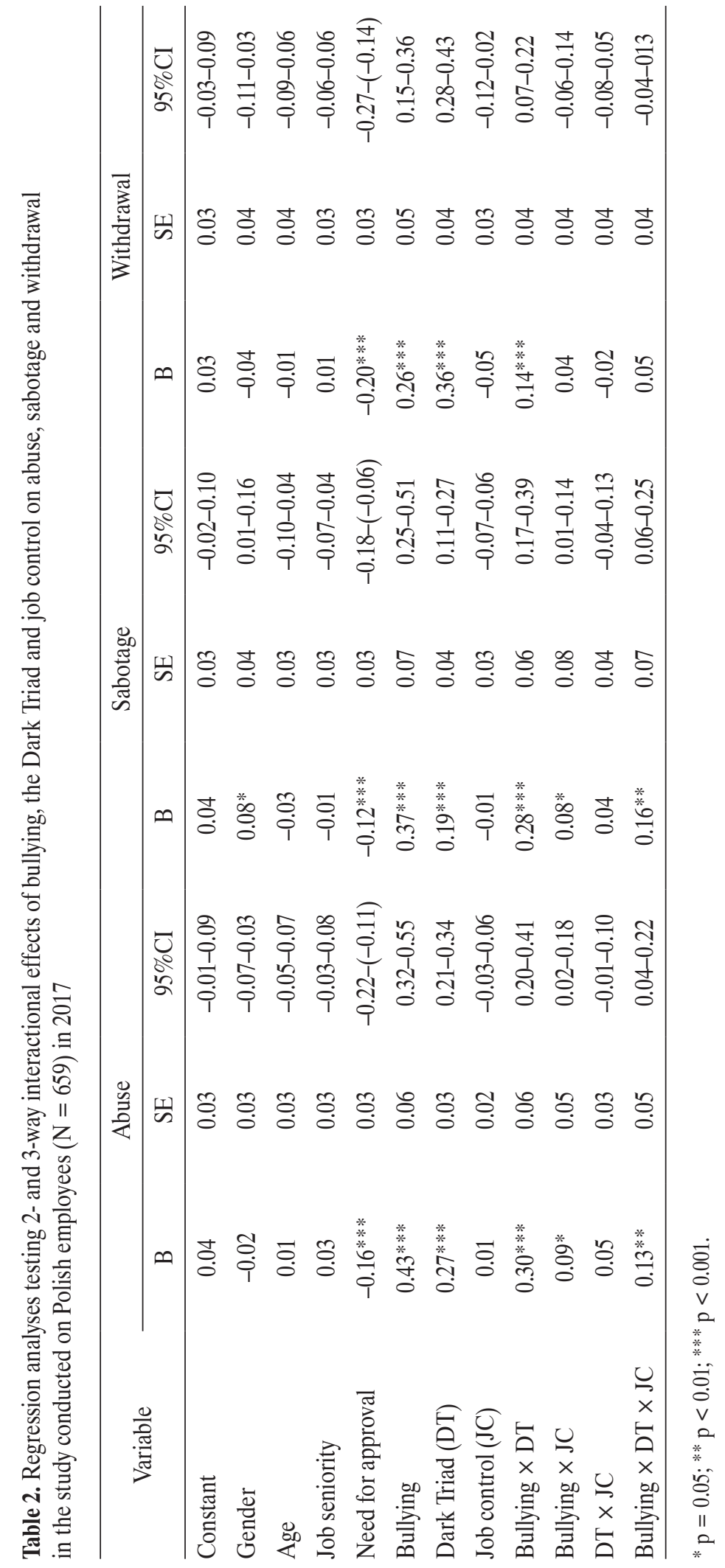




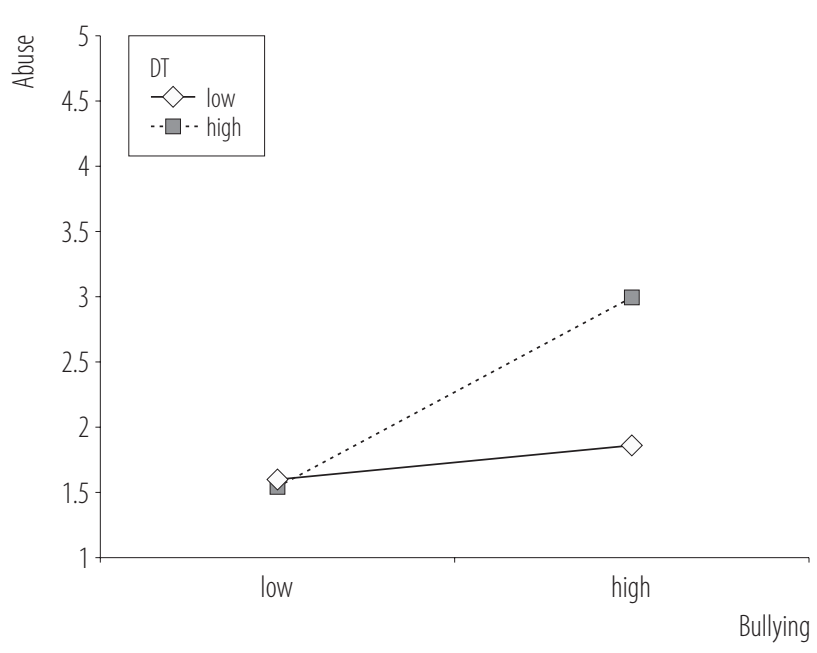

Figure 1. Two-way interaction between bullying and the Dark Triad predicting abuse in the study conducted on Polish employees $(\mathrm{N}=659)$ in 2017

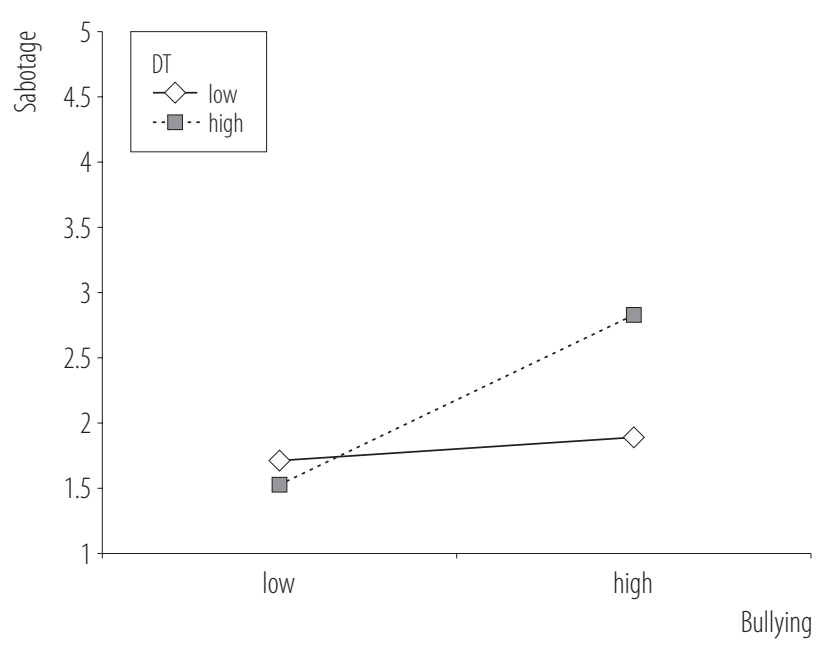

Figure 2. Two-way interaction between bullying and the Dark Triad predicting sabotage in the study conducted on Polish employees $(\mathrm{N}=659)$ in 2017

The moderated moderation effect was confirmed partially (Table 2). The 3-way interaction between bullying, DT and JC predicted abuse ( $\mathrm{B}=0.13,95 \% \mathrm{CI}: 0.04-0.22)$ and sabotage ( $\mathrm{B}=0.16,95 \% \mathrm{CI}: 0.06-0.25)$, but not withdrawal ( $\mathrm{B}=0.05$, n.s.). The 2 moderated moderation effects were confirmed by means of F-test for a significant change in $\mathrm{R}^{2}$ values: $\mathrm{F}(1,655)=20.57, \mathrm{p}<0.001 ; \Delta \mathrm{R}^{2}=0.02$ (for abuse) and $F(1,655)=28.21, p<0.001 ; \Delta R^{2}=0.03$ (for

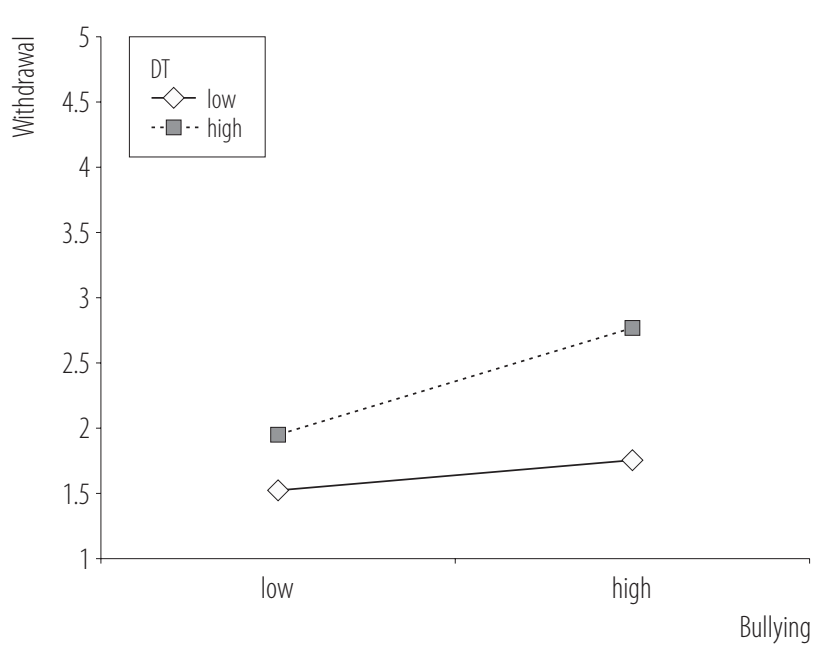

Figure 3. Two-way interaction between bullying and the Dark Triad predicting withdrawal in the study conducted on Polish employees $(\mathrm{N}=659)$ in 2017

sabotage). The findings indicate that JC intensifies the moderation effect of DT on the bullying-active CWB link. Abuse (Figure 4) and sabotage (Figure 5) increased along with the increase in bullying, but this effect turned out to be the strongest when DT and JC were also high. The test of slope differences indicated that, in conditions of high bullying, abuse was more frequent for individuals with high levels of DT and JC, compared with individuals with low DT but high JC $(\mathrm{t}=2.71, \mathrm{p}<0.01)$, and with low levels of DT and JC $(t=3.10, p<0.001)$. For individuals with high DT, the level of abuse was not different regardless of whether JC was low or high $(t=1.07, p=0.28)$.

A similar pattern was observed in relation to sabotage. When bullying was high, individuals with high levels of DT and JC engaged in this behavior more frequently than individuals with low DT but high JC $(\mathrm{t}=2.77$, $\mathrm{p}<$ $0.01)$, as well as with low levels of DT and JC $(t=2.93$, $\mathrm{p}<0.01)$. Between individuals with high DT, there were no significant differences in the level of sabotage, regardless of the level of JC $(t=1.22, p=0.22)$. The 3-way interaction effect was not obtained for the passive form of CWB (Figure 6). The combination of high/low levels of bullying, DT and JC did not predict withdrawal. The 


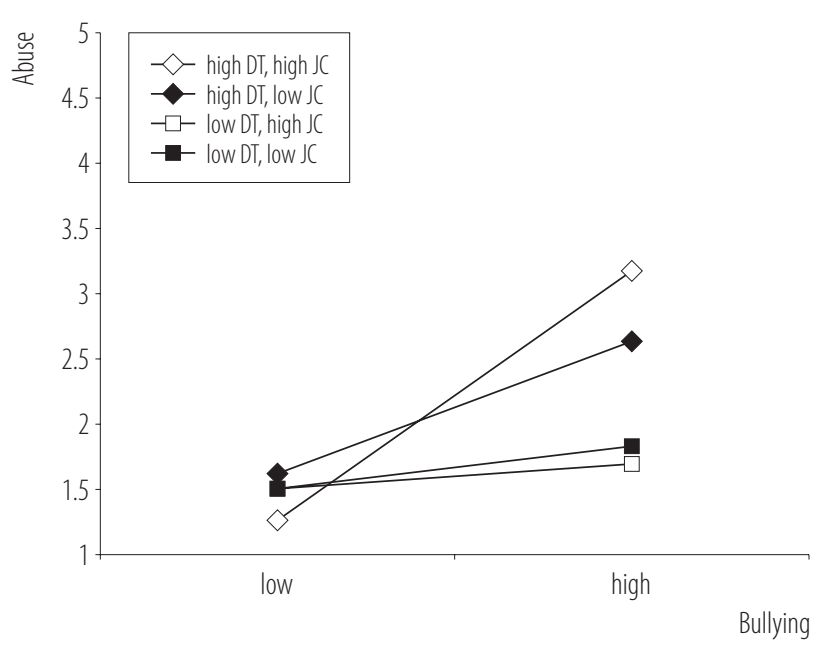

Figure 4. Three-way interaction between bullying, the Dark Triad and job control predicting abuse in the study conducted on Polish employees $(\mathrm{N}=659)$ in 2017

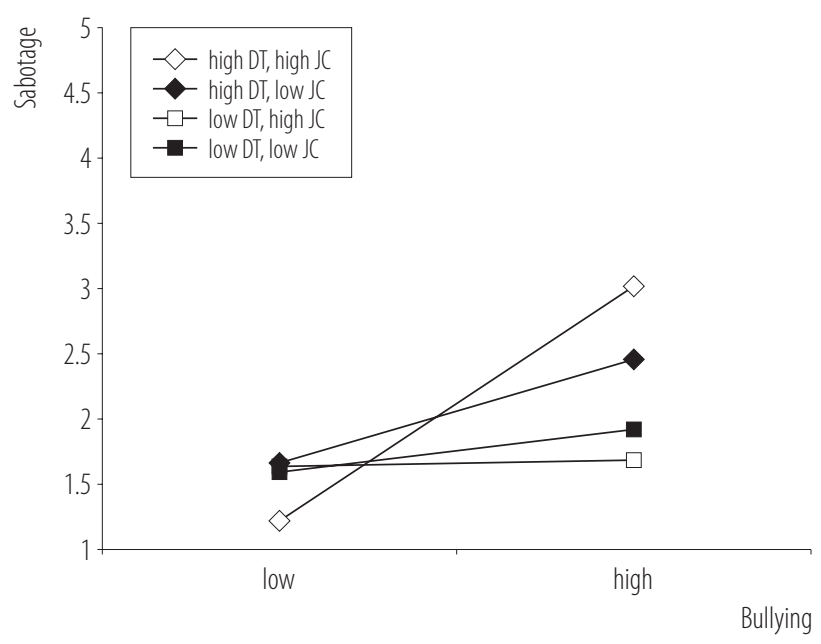

Figure 5. Three-way interaction between bullying, the Dark Triad and job control predicting sabotage in the study conducted on Polish employees $(\mathrm{N}=659)$ in 2017

test of slope differences indicated that the 4 slopes did not differ significantly from each other. The findings partially supported H3. It was expected (H4) that the 3-way interaction effect would be stronger for active types of CWB, as compared to the passive type of CWB. The significance of the moderated moderation effects for abuse and sabotage, and a lack of significance for withdrawal, confirm $\mathrm{H} 4$.

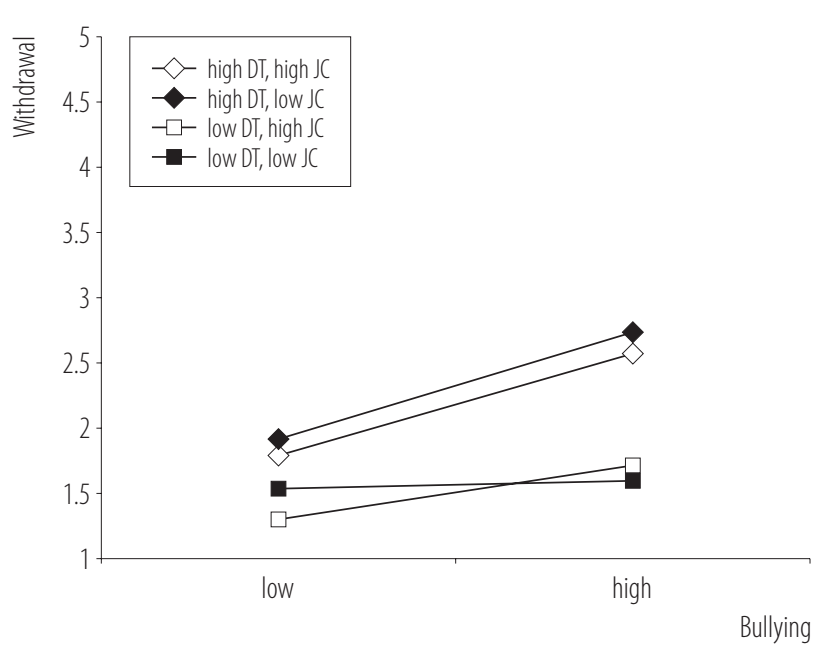

Figure 6. Three-way interaction between bullying, the Dark Triad and job control predicting withdrawal (a non-significant effect) in the study conducted on Polish employees $(\mathrm{N}=659)$ in 2017

\section{DISCUSSION}

The current study is aimed at identifying some job-related (bullying at work and job control) and personality-related (the Dark Triad) predictors of active and passive forms of $\mathrm{CWB}$, as well as at explaining the complex relationships between them. The findings showed that bullying was related to CWB, but it was more strongly associated with active forms of CWB (abuse and sabotage) than with the passive one (withdrawal). These results are consistent with the work frustration-aggression model [66], which assumes that, under high organizational mistreatment conditions, employees commonly tend to enact impulsive, irrepressible and overtly aggressive forms of revenge, which are aimed directly towards the source of frustration. The main effect of JC on CWB was not observed. Previous studies on JC relationships with CWB have yielded inconsistent results, with some researchers reporting negative (though poor) relationships [13], and others indicating positive relationships [64]. In all probability, the modifying variables include personality traits (e.g., self-control) and other types of organizational resources (e.g., social support and psychological climate), and personal resources (e.g., locus of control, self-efficacy). These interact 
with JC and together affect CWB. This is confirmed by some studies [14,43].

Certain correlations between DT and the 3 analyzed behaviors were found. The findings are coherent with the results of 2 meta-analyses [79,12]. The correlations of DT with abuse and withdrawal were a little stronger than with sabotage. Previous research has shown that each of the 3 "dark traits" is associated somehow differently with CWB [12] and the tactics of workplace manipulation [55]. Therefore, an analysis of the role of each of the dark traits in predicting CWB was conducted additionally. The findings showed that Machiavellianism (compared with narcissism and psychopathy) had the strongest associations with the 3 measured types of CWB. These findings are consistent with the results obtained by other researchers [67,79].

With regard to the moderation effect, the DT was shown to increase the negative impact of bullying on harmful behavior. It means that, under conditions of high job stress, individuals high in these traits are particularly likely to engage in counterproductive activities. These results are consistent with the findings of previous research $[9,57]$. It was observed that DT traits had a greater moderation effect on the negative impact of job stressors in the case of active, rather than passive, forms of CWB. An additional analysis showed that this effect concerned each of the DT traits. Even though the pattern holds true for all individual DT traits, the reasons that lead Machiavellian, narcissistic and psychopathic individuals to react with aggression may vary. While psychopathic employees tend to respond aggressively in confrontational situations, narcissists are more likely to do so when their self-esteem is under threat [80]. In addition, the latter tend to be more cautious and "mild" in their response. They are also more likely to consider the potential consequences of their behavior.

Employees who show psychopathic traits tend to resort to "hard" manipulation tactics (e.g., confrontation), while narcissists typically prefer "soft" measures (e.g., ingratiation). Those with a high degree of Machiavellianism, conversely, employ both types depending on the situation [55]. Moore et al. [81] also showed that Machiavellians display a much higher degree of moral disengagement than other individuals. Moral disengagement temporarily relaxes moral norms and standards and, thus, makes it significantly easier for them to engage in unethical behavior [82]. Job control also moderated the connections of bullying with abuse and sabotage, but not with withdrawal. More specifically, the higher the level of bullying, the higher were the levels of abuse and sabotage, but mainly when JC was also high. However, weaker moderation effects were observed for JC than for DT. The intensifying (rather than buffering) effect of JC observed in the study is inconsistent with the claims of some authors [59] who advocate that CWB often stems from the sense of helplessness caused by the employees' inability to influence their own work environment, e.g., the procedures of granting bonuses and rewards, promotions and remuneration. In this light, such tactics are understood as a way to vent negative emotions and restore a symbolic sense of JC [58]. According to Allen and Greenberg [60], under stressful conditions, individuals with a lower sense of JC tend to modify their environment and restore control through destructive acts. Conversely, a stronger sense of JC is linked to fewer organizational constraints and a greater leeway for action, which creates more opportunities for engagement in CWB, and decreases the risk that such behavior will be detected and punished. This is supported by some studies which show a positive correlation between JC and CWB [64], as well as an intensifying effect of JC on the link between job stressors and CWB [13,15].

The findings have also confirmed a 3-way interaction effect (bullying $\times$ DT $\times$ JC). The combination of high levels of job stress, high DT traits and high JC have resulted in the highest degree of CWB. In other words, job stressors were found to intensify CWB particularly in individuals 
with high levels of DT traits and JC. The current findings confirm the suggestion made by some researchers that for employees with high DT traits, high JC contributes to an increase in CWB $[62,18]$. It is worth noting that the 3-way interactional effect was observed only for the active forms of CWB (abuse and sabotage), and not for the passive one (withdrawal). This means that, in situations of high job stress and high JC, individuals with high levels of DT traits are more likely to engage in hostile, rather than instrumental, forms of aggressive behavior. It could be the case that, in situations of low autonomy and freedom, accompanied by high risks of sanctions and high potential consequences for unethical behavior, employees with pronounced DT traits may resort to withdrawal tactics. As JC increases, however, they tend to turn to more direct forms of organizational revenge.

\section{Limitations and future directions}

It is worth mentioning the limitations of the current study. One of these has to do with the measurement method. All measured variables were assessed by self-reports. Therefore, the results might be contaminated by common method variance or a self-report bias [83]. Furthermore, the self-reporting tool has been repeatedly criticized for measuring declarations rather than concrete behavior or, to be more precise, the frequency with which respondents admit to engaging in counterproductive work behavior. Respondent declarations are affected by many variables, such as the social approval, the acceptance of CWB in organizational standards, or the perceived harshness and likelihood of sanctions, as well as by individual personality traits, e.g., the tendency to lie and the degree of self-control [84]. Researchers also point out that the mean levels obtained for most items in CWB questionnaires tend to be low. The reason for this is that respondents are unlikely to admit that they engage in such behavior [85]. Certain types of CWB (e.g., theft) are regulated by law and employees tend to deny them for fear of punishment. In other cases, however, they simply find it difficult to admit to wrongdoing, even to themselves. Doing so would probably involve the rise of negative thoughts about themselves and, as a consequence, experiencing various unpleasant emotions.

The alternative CWB measurement method, based on reports by superiors and colleagues, also has its limitations. As stated by Fox et al. [86], superiors and colleagues are likely to detect only some counterproductive acts, since these are mostly carried out in secret. In a meta-analysis study, Berry et al. [87] compared CWB data obtained from self-reports with evaluations by superiors and colleagues. The mean corrected correlation coefficient for CWB, as measured by these 2 methods, was shown to be moderate $(\mathrm{r}=0.38)$. In addition, the mean values for CWB measured by self-reporting scales proved higher than those reported by other employees [87]. This seems to suggest that superiors and colleagues tend to underestimate the occurrence of CWB. The figures can be treated as an argument to support the greater validity of self-reports as compared to external evaluation.

Another limitation has to do with the fact that the analysis of moderation in the current study was based on cross-sectional surveys, rather than on a cross-lagged study. Negative organizational behaviors are very dynamic and emerge as a result of long-term job stressors, personality traits and the emotions that they engender. The orientation of the cause-and-effect between a job stressor and CWB is not completely clear. According to the results of 2 recent crosslagged studies, there is a specific spiral gain between bullying at work and CWB $[8,88]$. For instance, Simon et al. [88] demonstrated that abusive supervision was positively related to the active CWB at baseline and had a lagged relation to the passive types of CWB at follow-up. A high level of "reciprocal" CWB, however, leads to an increase in the abusive behavior of supervisors, as revealed in further measurements. Wei and Si [8] obtained similar results. Slightly different mechanisms of the active and passive types of CWB were observed. In the case of the active CWB, the 
effect of abusive supervision was mediated by anger, but in the case of the passive CWB the role of the mediator was played by anxiety [88]. The results of the abovementioned studies indicate different development mechanisms for the 2 types of CWB. They also suggest that a certain feedback exists between stress and CWB.

\section{CONCLUSIONS}

To conclude, it is worth mentioning both the cognitive and practical implications of the studies performed. The cognitive value of the study is checking the stressor-emotion model in Polish conditions, and its expansion with additional variables, important from the perspective of CWB antecedents. As regards the practical implications, the current study has demonstrated that, when experiencing mistreatment by other employees, the sense of JC in people with a higher level of DT can bring negative results for the organization. Most probably, this will be attributed to a stronger inclination of employees with such characteristics to respond with greater frustration and anger to the harm they experience. Such an outcome can also result from the inclination to be impulsive and to strongly engage in retaliatory practices. High levels of autonomy and freedom foster such behavior.

Employees with DT can find the involvement in harmful activities - when they experience a sense of humiliation or unfair treatment - as a particularly effective way of coping with stress, with a somewhat "therapeutic" effect. A health-promoting effect of counterproductive behavior was demonstrated in several research studies but DT characteristics were not taken into account $[21,65]$. Providing employees high in both DT and JC with other organizational resources can be a form of CWB counteraction. Such resources may include social support, coaching and a favorable organizational climate. It is possible that, owing to the "richness" of job resources, people will activate other, more productive methods of coping with stress, e.g., focusing on their tasks.

\section{REFERENCES}

1. Spector PE, Fox S. The stressor-emotion model of counterproductive work behaviour (CWB). In: Fox S, Spector PE, editors. Counterproductive work behaviour: investigations of actors and targets. Washington: DC: APA Press; 2005.

2. Linstead S, Marechal G, Griffin RW. Theorizing and researching the dark side of organization. Organ Stud. 2014;35(2): 165-88, https://doi.org/10.1177/0170840613515402.

3. Bauer JA, Spector, PE. Discrete negative emotions and counterproductive work behaviour. Hum Perform. 2015;28(4): 307-31, https://doi.org/10.1080/08959285.2015.1021040.

4. Einarsen S. The nature and causes of bullying at work. Int J Manpower. 1999;20:16-27.

5. Bibi Z, Karim J. Workplace incivility and counterproductive work behaviour. Moderating role of emotional intelligence. Pak J Psychol Res. 2013;28(2):317-34.

6. Mitchell MS, Ambrose ML. Abusive supervision and workplace deviance and the moderating effects of negative reciprocity beliefs. J Appl Psychol. 2007;92(4):1159-68, https:// doi.org/10.1037/0021-9010.92.4.1159.

7. Sulea C, Fine S, Fischmann G, Sava FA, Dumitru C. Abusive supervision and counterproductive work behaviours: The moderating effects of personality. J Pers Psychol. 2013;12(4): 196-200, https://doi.org/10.1027/1866-5888/a000097.

8. Wei F, Si S. Tit for tat? Abusive supervision and counterproductive work behaviours. The moderating effects of locus of control and perceived mobility. Asian J Manag. 2013;30(1): 281-96, https://doi.org/10.1007/s10490-011-9251-y.

9. Boddy CR. Corporate psychopaths, conflict, employee affective well-being and counterproductive work behavior. J Bus Ethics. 2014;121(1):107-21, https://doi.org/10.1007/s10551-013-1688-0.

10. Meier LL, Semmer NK. Lack of reciprocity, narcissism, anger, and instigated workplace incivility: A moderated mediation model. Eur J Work Organ Psy. 2012;22(4):461-75, https://doi.org/10.1080/1359432X.2012.654605.

11. Meurs JA, Fox S, Kessler S, Spector PE. It's all about me: The role of narcissism in exacerbating the stressor-counterproductive work behaviour relationship. Work Stress. 
2013;27(4):368-82, https://doi.org/10.1080/02678373.2013.8 49776.

12. O'Boyle EH, Forsyth DR, Banks GC, McDaniel MA. A meta-analysis of the Dark Triad and work behaviour. A social exchange perspective. J Appl Psychol. 2012;97(3):557-79, https://doi.org/10.1037/a0025679.

13. Fox S, Spector PE, Miles D. Counterproductive work behaviour $(\mathrm{CWB})$ in response to job stressors and organizational justice: Some mediator and moderator tests for autonomy and emotions. J Vocat Behav. 2001;59(3):1-19, https://doi. org/10.1006/jvbe.2001.1803.

14. Smoktunowicz E, Baka L, Cieslak R, Nichols CF, Benight CC, Luszczynska A. Explaining counterproductive work behaviours among police officers: The indirect effects of job demands are mediated by burnout and moderated by job control and social support. Hum Perform. 2015;28(4):332-50, https://doi.org/10.1080/08959285.2015.1021045.

15. Tucker JS, Sinclair RR, Mohr CD, Adler AB, Thomas JL, Salvi AD. Stress and counterproductive work behaviour: Multiple relationships between demands, control, and soldier indiscipline over time. J Occup Health Psych. 2009;14(3):257-71, https://doi.org/10.1037/a0014951.

16. Skarlicki DP, Folger R. Retaliation in the workplace: The roles of distributive, procedural, and interactional justice. J Appl Psychol. 1997;82(2):434-43.

17. Hobfoll SE. Conservation of resources: A new attempt at conceptualizing stress. Am Psychol. 1989;44(3):513-24.

18. Cohen A. Are they among us? A conceptual framework of the relationship between the dark triad personality and counterproductive work behaviors (CWBs). Hum Resour Manage R. 2015;26(1):69-85, https://doi.org/10.1016/j.hrmr.2015.07.003.

19. Robinson SL, Bennett RJ. A typology of deviant workplace behaviours: A multidimensional scaling study. Acad Manage J. 1995;38(3):555-72, https://doi.org/10.2307/256693.

20. Spector PE, Fox S, Penney LM, Bruursema K, Goh A, Kessler $\mathrm{S}$. The dimensionality of counterproductivity: Are all counterproductive behaviours created equal? J Vocat Behav. 2006;68(3):446-60, https://doi.org/10.1016/j.jvb.2005.10.005.
21. Krischer MM, Penney LM, Hunter EM. Can counterproductive work behaviours be productive? CWB as emotion focused coping. J Occup Health Psych. 2010;15(2):154-66, https://doi.org/10.1037/a0018349.

22. Carpenter N, Berry CM. Are counterproductive work behaviour and withdrawal empirically distinct? A meta-analytic investigation. J Manage. 2017;43(3):834-63, https://doi. org/10.1177/0149206314544743.

23. Crino MD. Employee sabotage: A random or preventable phenomenon? J Manag Issues. 1994;6(3):311-30.

24. Chen PY, Spector PE. Relationships of work stressors with aggression, withdrawal, theft and substance use: An exploratory study. J Occup Organ Psych. 1992;65(3):177-84.

25. Bowling NA, Eschleman KJ. Employee personality as a moderator of the relationships between work stressors and counterproductive work behavior. J Occup Health Psych. 2010;15(1):91-103, https://doi.org/10.1037/a0017326.

26. Bennett RJ, Robinson SL. Development of a measure of workplace deviance. J Appl Psychol. 2000;85(3):349-60, https://doi.org/10.1037/0021-9010.85.3.349.

27. Banks GC, Whelpley CE, In-Sue O. (How) are emotionally exhausted employees harmful? Int J Stress Manage. 2012;19(3):198-216, https://doi.org/10.1037/a0029249.

28. Romano C. Workplace violence takes a deadly turn. Manag Rev. 1994(1);83:5.

29. Berry CM, Ones DS, Sackett PR. Interpersonal deviance, organizational deviance, and their common correlates: A review and meta-analysis. J Appl Psychol. 2007;92(2):410-24, https://doi.org/10.1037/0021-9010.92.2.410.

30. Hershcovis MS, Barling J. A relational perspective on workplace aggression: An examination of perpetrators and targets. In: Langdan-Fox J, Cooper C, Klimoski R, editors. Research companion to RESEARCH REPORTS 1409 the dysfunctional workplace: Management challenges and symptoms. Cheltenham: Edward Elgar Publishing Ltd; 2007. p. 268-84.

31. Van den Broeck A, Sulea C, Vander Elst T, Fischmann G, Iliescu D, De Witte H. The mediating role of psychological needs 
in the relation between qualitative job insecurity and counterproductive work behavior. Career Dev Int. 2014;19(5):52547, https://doi.org/10.1108/CDI-05-2013-0063.

32. Ferguson M, Carlson D, Hunter EM, Whitten D. A twostudy examination of work-family conflict, production deviance and gender. J Vocat Behav. 2012;81(2):245-58, https:// doi.org/10.1016/j.jvb.2012.07.004.

33. Einarsen S, Hoel H, Zapf D, Cooper CL. The concept of bullying at work. In: Einarsen S, Hoel H, Zapf D, editors. Bullying and emotional abuse in the workplace: International perspectives in research and practice. London: Taylor \& Francis; 2003. p. 3-30.

34. Penney LM, Spector PE. Job stress, incivility, and counterproductive work behaviour (CWB): The moderating role of negative affectivity. J Organ Behav. 2005;26(7):777-96, https://doi.org/10.1002/job.336.

35. Balducci C, Schaufeli WB, Fraccaroli F. The job demands - resources model and counterproductive work behaviour: The role of job-related affect. Eur J Work Organ Psychol. 2011;20(4): 467-96, https://doi.org/10.1080/13594321003669061.

36. Baka $Ł$. How do negative emotions regulate the effects of workplace aggression on counterproductive work behaviours? Pol Psychol Bul. 2015;46(3):325-36, https://doi. org/10.1515/ppb-2015-0040.

37. Karasek RA, Theorell T. Healthy work. Stress, productivity and the reconstruction of working life. New York: Basic Books; 1990.

38. De Jonge J, Dormann C. The DISC Model: Demand-Induced Strain Compensation mechanisms in job stress. In: Dollard MF, Winefield HR, Winefield AH, editors. Occupational stress in the service professions. London: Taylor \& Francis; 2003. p. 43-74.

39. Schaufeli WB, Bakker AB. Job demands, job resources and their relationship with burnout and engagement: A multisample study. J Organ Behav. 2004;25(3):293-315. https:// doi.org/10.1002/job.248.

40. Spector PE. The relationship of personality to counterproductive work behavior (CWB): An integration of perspectives. Hum Resour Manage R. 2011;21(4):342-52, https://doi.org/10.1016/j.hrmr.2010.10.002

41. Chao JMC, Cheung FYL, Wu AMS. Psychological contract breach and counterproductive workplace behaviours: Testing moderating effect of attribution style and power distance. Int J Hum Resour Man. 2011;22(4):763-77, https:// doi.org/10.1080/09585192.2011.555122.

42. Douglas SC, Martinko MJ. Exploring the role of individual differences in the prediction of workplace aggression. J Appl Psychol. 2001;86(4):547-59, https://doi.org/10.1037/00219010.86.4.547.

43. Sprung JM, Jex SM. Work locus of control as a moderator of the relationship between work stressors and counterproductive work behaviour. Int J Stress Manage. 2012;19(4):27291, https://doi.org/10.1037/a0030320.

44. Paulhus DL, Williams K. The Dark Triad of personality: Narcissism, Machiavellianism, and Psychopathy. J Res Pers. 2002;36(1):556-68, https://doi.org/10.1016/S0092-6566 (02)00505-6.

45. Christie R, Lehmann S. The structure of Machiavellian orientations. In: Christie R, Geis FL, editors. Studies in Machiavellianism. New York: Academic Press; 1970.

46. Rauthmann JF, Will T. Proposing a multidimensional Machiavellianism conceptualization. Soc Behav Personal. 2011; 39(3):391-404, https://doi.org/10.2224/sbp.2011.39.3.391.

47. Kernberg OF. An ego psychology object relations theory of the structure and treatment of pathologic narcissism: An overview. Psychiat Clin N Am. 1989;12:723-9.

48. Morf CC, Rhodewalt F. Unraveling the paradoxes of narcissism: A dynamic self-regulatory processing model. Psychol Inq. 2001;12(4):177-96, https://doi.org/10.1207/S15327965PLI1204_1.

49. Hare RD, Neumann CS. Psychopathy: Assessment and forensic implications. Can J Psychiat. 2009;54(12):791-802, https://doi.org/10.1177/070674370905401202.

50. Spain SM, Harms PD, Lebreton JM. The dark side of personality at work. J Organ Behav. 2013;35(1):1-20, https:// doi.org/10.1002/job.1894. 
51. Hogan R. Personality and the Fate of Organizations. Mahwah: Erlbaum; 2007.

52. Pilch I. Makiawelizm, narcyzm, psychopatia: Ciemna Triada jako próba opisania osobowości ekslpoatatora [Machiavellianism, narcicissm and psychopathy. Dark Triad as the attempt of personality description]. Chowanna. 2014;2:16581. Polish.

53. DeShong HL, Grant DM, Mullins-Sweatt SN. Comparing models of counterproductive workplace behaviours: The five-factor model and the dark triad. Pers Indiv Differ. 2015;74(1):55-60, https://doi.org/10.1016/j.paid.2014.10.001.

54. Scherer KT, Baysinger M, Zolynsky D, LeBreton JM. Predicting counterproductive work behaviours with sub-clinical psychopathy. Beyond the five factor model of personality. Pers Indiv Differ. 2013;55(3):300-5, https://doi.org/10.1016/ j.paid.2013.03.007.

55. Jonason PK, Slomski S, Partyka J. The Dark Triad at work. How toxic employees get their way. Pers Indiv Differ. 2012;52(3):449-53, https://doi.org/10.1016/j.paid.2011.11.008.

56. Wu J, LeBreton JM. Reconsidering the dispositional basis of counterproductive work behaviour: The role of aberrant personality traits. Pers Psychol. 2011;64(3):593-626, https:// doi.org/10.1111/j.1744-6570.2011.01220.x.

57. Penney LM, Spector PE. Narcissism and counterproductive work behaviour (CWB). Do bigger egos mean bigger problems? Int J Select Assess. 2002;10(1-2):126-34, https://doi. org/10.1111/1468-2389.00199.

58. Karasek R. Job Content Questionnaire and user's guide. Lowell, MA: Department of Work Environment: University of Massachusetts; 1985.

59. Fox S, Spector PE. The many roles of control in a stressor - emotion theory of counterproductive work behaviour. In: Perrewe PL, Ganster D, editors. Employee health, coping and methodologies. Amsterdam: Elsevier; 2006.

60. Allen VL, Greenberg DB. Destruction and perceived control. In: Baum A, Singer JE, editors. Applications of personal control. Hillsdale, NJ: Lawrence Erlbaum Associates; 1980. p. 85-109.
61. Edwards JR, Caplan RD, Harrison RV. Person-environment fit theory: Conceptual foundations, empirical evidence, and directions for future research. In: Cooper CL, editor. Theories of organizational stress. Oxford: Oxford University Press; 1998. p. 28-67.

62. Grijalva E, Newman DA. Narcissism and counterproductive work behaviour (CWB): Meta-analysis considering collectivist culture, Big Five personality, and narcissism's facet structure. Appl Psychol-Int Rev. 2015;64(1):93-126, https://doi. org/10.1111/apps.12025.

63. Berkowitz L. Affective aggression: The role of stress, pain, and negative affect. In: Geen RG, Donnerstein E, editors. Human aggression: Theories, research and implications for social policy. San Diego, CA: Academic; 1998. p. 49-72.

64. Wilson RA, Perry SJ, Witt LA, Griffeth RW. The exhausted short-timer: Leveraging autonomy to engage in production deviance. Hum Relat. 2015;68(11):1693-711, https://doi.org/ $10.1177 / 0018726714565703$.

65. Shoss MK, Jundt DK, Kobler A, Reynolds C. Doing bad to feel better? An investigation of within and between-person perceptions of Counterproductive Work Behaviour as a coping tactic. J Bus Ethics. 2015;137(3):571-87, https://doi. org/10.1007/s10551-015-2573-9.

66. Fox S, Spector PE. A model of work frustration-aggression. J Organ Behav. 1999;20(4):915-31, https://doi.org/10.1002/ (SICI)1099-379(199911).

67. Jonason P, Webster G. The dirty dozen: A concise measure of the Dark Triad. Psychol Assessment. 2010;22(2):420-32, https://doi.org/10.1037/a0019265.

68. Egan V, Hughes N, Palmer EJ. Moral disengagement, the dark triad and unethical consumer behaviour. Pers Indiv Differ. 2015;76(1):123-8, https://doi.org/10.1016/j.paid.2014. 11.054.

69. Babiak P, Hare RD. Snakes in suits: When psychopaths go to work. New York: HarperCollins; 2006.

70. Birenbaum M, Montag J. Style and substance in social desirability scales. Eur J Personality. 1989;3(1):47-59, https://doi. org/10.1002/per.2410030106. 
71. Einarsen S, Raknes B. Harassment in the workplace and the victimization of men. Violence Vict. 1997;12(3):247-63, https://doi.org/10.1891/0886-6708.12.3.247

72. Warszewska-Makuch, M. Polish adaptation of NAQ questionnaire. Bezp Pr. 2007;12(2):16-20.

73. Żołnierczyk-Zreda, D, Bedyńska S. Psychometric properties of the Polish version of the Karasek's Job Content Questionnaire. Int J Occup Saf Ergo. 2014;20(4):583-93, https://doi. org/10.1080/10803548.2014.11077075.

74. Czarna AZ, Jonason PK, Dufner M, Kossowska M. The Dirty Dozen Scale: Validation of a Polish version and extension of the nomological net. Front Psychol. 2016;7(445), https://doi.org/10.3389/fpsyg.2016.00445

75. Baka \&, Derbis R, Walczak R. Psychometric properties of the Polish version of CWB-C. Czasopismo Psychol. 2015;21(4):163-71, https://doi.org/10.14691/CPPJ.21.2.163.

76. Drwal RŁ, Wilczynska J. Social Approbation Questionnaire In: Drwal RL, Brzozowski P, Oles P, editors. Adaptation of Personality Questionnaires. Warsaw: Polish National Publishing House PWN; 1995. p. 57-66.

77. Hayes AF. An introduction to mediation, moderation, and conditional process analysis: A regression-based approach. New York: Guilford Press; 2013.

78. Dawson JF. Moderation in management research: What, why, when and how. J Bus Psychol. 2014;29(1):1-19, https:// doi.org/10.1007/s10869-013-9308-7

79. Kish-Gephart JJ, Harrison DA, Trevino LK. Bad apples, bad cases, and bad barrels: Meta-analytic evidence about sources of unethical decisions at work. J Appl Psychol. 2010;95(1):131, https://doi.org/10.1037/a0017103.

80. Jones DN, Paulhus DL. Different provocations trigger aggression in narcissists and psychopaths. Soc Psychol Pers Sci. 2010;1(1):12-8, https://doi.org/10.1177/1948550609347591.
81. Moore C, Detert JR, Trevino LK, Baker VL, Mayer DM. Why employees do bad things: Moral disengagement and unethical organizational behaviour. Pers Psychol. 2012;69(1):1-48, https://doi.org/10.1111/peps.12137.

82. Bandura A. Moral Disengagement in the Perpetration of Inhumanities. Pers Soc Psychol Rev. 1999;3:193-209, https:// doi.org/10.1207/s15327957pspr0303_3.

83. Podsakoff PM, MacKenzie SB, Podsakoff NP. Sources of method bias in social science research and recommendations on how to control it. Annu Rev Psychol. 2012;63:53969, https://doi.org/10.1146/annurev-psych-120710-100452.

84. Fox S, Spector P, Goh A, Bruursema K, Kessler S. The deviant citizen: Measuring potential positive relations between counterproductive work behaviour and organizational citizenship behaviour. J Occup Organ Psych. 2012;85(1):199220, https://doi.org/10.1111/j.2044-8325.2011.02032.x.

85. Sackett PR, DeVore CJ. Counterproductive behaviours at work. In: Anderson N, Ones DS, Sinangil HK, Viswesvaran $\mathrm{C}$, editors. Handbook of industrial, work and organizational psychology. Vol. 1. Thousand Oaks, CA: Sage; 2001.

86. Fox S, Spector PE, Goh A, Bruursema K. Does your coworker know what you're doing? Convergence of self and peer-reports of counterproductive work behaviour. Int JStress Manage. 2007;14:41-60, https://doi.org/10.1037/10725245.14.1.41.

87. Berry CM, Carpenter NC, Barratt CL. Do other-reports of counterproductive work behaviour provide an incremental contribution over self-reports? A meta-analytic comparison. J Appl Psychol. 2012;97(3):613-36, https://doi.org/10.1037/ a0026739.

88. Simon LS, Hurts C, Kelley K, Judge T. Understanding cycles of abuse. A multimotive approach. J Appl Psychol. 2015;100(6):1798-810, https://doi.org/10.1037/ap10000031.

This work is available in Open Access model and licensed under a Creative Commons Attribution-NonCommercial 3.0 Poland License - http://creativecommons.org/ licenses/by-nc/3.0/pl/deed.en. 